\title{
Homocysteine Lowering with B Vitamins for Stroke Prevention-A History
}

\author{
J David Spence \\ Stroke Prevention \& Atherosclerosis Research Centre, Robarts Research Institute, Western University, London, Ontario, Canada
}

DOI: https://doi.org/10.17925/USN.2018.14.1.35

E arly trials of B vitamin therapy to lower plasma total homocysteine (tHcy) reported no reduction of stroke with high doses of folate/B6

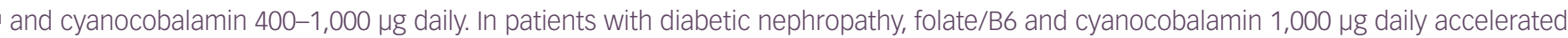
the decline of renal function and doubled cardiovascular events. Patients with renal failure have high cyanide levels. The French Supplementation with FOlate, vitamin B6 and B12 and/or OMega-3 fatty acids (Su.Fol.OM3) trial-with the best renal function of the early trials and the lowest dose of cyanocobalamin (20 $\mu \mathrm{g}$ daily)—reported a 43\% reduction of stroke. Then the China Stroke Primary Prevention Trial (CSPPT) reported that folic acid alone reduced stroke and was beneficial even in patients with impaired renal function. Patient-level data from the Vitamin Intervention to Prevent Stroke (VISP) and VITAmins TO Prevent Stroke (VITATOPS) trials and meta-analyses stratified by renal function and dose of cyanocobalamin confirmed that harm from cyanocobalamin among participants with renal impairment obscured the benefit of $B$ vitamins in the early trials. It does seem that B vitamins reduce the risk of stroke. In the era of folate fortification, B12 is the main nutritional determinant of tHcy, and metabolic B12 deficiency is very common and usually missed. Therefore, folate alone is not the optimal way to lower tHcy: the use of folate (and possibly B6) with methylcobalamin or oxocobalamin should be considered.

\section{Keywords}

Homocysteine, B vitamins, cyanocobalamin, renal function, stroke

Disclosures: J David Spence has nothing to declare in relation to this article.

Review Process: This article is a short opinion piece and has not been submitted to external peer reviewers but was reviewed for accuracy by the editorial board before publication.

Compliance with Ethics: This article includes a review of the literature and did not involve any studies with human or animal subjects performed by the author.

Authorship: The named author meets the criteria of the International Committee of Medical Journal Editors for authorship for this manuscript, takes responsibility for the integrity of the work as a whole and has given final approval for the version to be published.

open Access: This article is published under the Creative Commons Attribution Non-commercial License, which permits any non-commercial use, distribution, adaptation and reproduction provided the original author and source are given appropriate credit. (c) The Author 2018

Received: March 25, 2018

Published Online: April 9, 2018

Citation: US Neurology. 2018;14(1):35-39

Correspondence: I David Spence, Stroke Prevention \& Atherosclerosis Research Centre, Robarts Research Institute, Western University, 1400 Western Road,

London, ON Canada N6G 2V4. E: dspence@robarts.ca

Support: No funding was received in

the publication of this article.
Despite substantial evidence to the contrary, there is still a widespread belief that B vitamins to lower plasma total homocysteine (tHcy) do not prevent stroke. This belief is based on the failure of early clinical trials to show a reduction of stroke with B vitamin therapy. However, it is increasingly clear that harm from cyanocobalamin among participants with impaired renal function obscured the benefit of B vitamin therapy in these early trials. Table 1 shows the timeline of the history of B vitamin therapy for stroke prevention by lowering of tHcy. ${ }^{1-15}$

The biological plausibility of the hypothesis that lowering tHcy with vitamin therapy should reduce the risk of stroke was overwhelming. ${ }^{16}$ McCully first suggested in $1969^{1}$ that high levels of tHcy may accelerate atherosclerosis based on findings in patients with severe hyperhomocysteinemia in patients homozygous for cystathionine synthase deficiency. In 1986, Boers et al. ${ }^{2}$ reported that patients with premature coronary disease were more likely to have high tHcy. By 1997 it was clear that there was a strong, graded increased risk of cardiovascular disease with higher levels of tHcy.3.17 There are several mechanisms by which elevated tHcy aggravates cardiovascular disease, and stroke in particular. High levels of homocysteine increase oxidative stress, impair endothelial function and increase thrombosis.

There are several B vitamins that are cofactors in the metabolism of homocysteine, as shown in Figure $1 .^{15}$ It was hypothesized, therefore, that a combination of folic acid and vitamin B12, which catalyze remethylation of homocysteine to methionine, and vitamin B6, which catalyzes transsulfuration to cystathionine, should lower levels of tHcy and thereby reduce cardiovascular events. ${ }^{18} \mathrm{~A}$ series of clinical trials ensued to test that hypothesis.

The first large trial that failed to show benefit of B vitamins was the Vitamin Intervention to Prevent Stroke (VISP) trial, ${ }^{4}$ published in 2004. There were several reasons why this trial did not show benefits of B vitamins. Firstly, folate fortification of the grain supply in North America coincided with the 1989 initiation of the trial, thereby negating the benefit of folic acid. Secondly, participants were not randomized to placebo versus active vitamins; they received high-dose B vitamins versus low dose $\mathrm{B}$ vitamins, and the low-dose regimen contained the recommended daily intake of vitamin B12 (6 $\mathrm{\mu g}$ daily). Thirdly, participants with a serum B12 below the reference range were given monthly injections of B12, regardless of which arm of the study to which they were randomized, thus preventing the benefit of B12 in the very participants who would have benefited most. 
Table 1: History of B vitamin therapy to lower homocysteine for stroke prevention

\begin{tabular}{|c|c|}
\hline Year & Development \\
\hline 1969 & Mccully described thrombosis, atherosclerosis and strokes in children with homocystinuria. ${ }^{1}$ \\
\hline 1986 & Boers et al. reported that $40 \%$ of patients with premature atherosclerosis had high tHcy. ${ }^{2}$ \\
\hline 1990s & High tHcy is demonstrated to be a clear graded risk factor for cardiovascular disease and interacts with smoking. ${ }^{3}$ \\
\hline 2004 & The VISP trial showed no benefit of high-dose versus low-dose folate/B6/B12 including cyanocobalamin $400 \mu \mathrm{g}$ daily in the high-dose arm. ${ }^{4}$ \\
\hline 2005 & $\begin{array}{l}\text { An analysis of a subgroup of the VISP trial, which excluded participants who received B12 injections and those in the lowest decile of eGFR }\left(48 \mathrm{~mL} / \mathrm{min} / 1.73 \mathrm{~m}{ }^{2}\right) \text {, } \\
\text { showed a } 34 \% \text { reduction of stroke, Ml and vascular death when comparing participants with good B12 absorption who received high dose vitamins versus those } \\
\text { with lower B12 at baseline who received low-dose vitamins. }{ }^{5}\end{array}$ \\
\hline 2006 & The NORVIT trial showed no benefit of B vitamins, and harm in the arm with cyanocobalamin 1,000 $\mu g$ daily. ${ }^{6}$ \\
\hline 2006 & $\begin{array}{l}\text { The HOPE- } 2 \text { trial, with better renal function than the earlier trials, showed a } 25 \% \text { reduction of stroke with B folate/B6 and 1,000 } \mu \text { daily of cyanocobalamin, but } \\
\text { reported this as a chance finding because there was no reduction of Ml.? }\end{array}$ \\
\hline 2006 & Loscalzo hypothesized that the reason for the null results of the trials was high doses of unmetabolized folic acid. ${ }^{8}$ \\
\hline 2010 & $\begin{array}{l}\text { The DIVINe study investigating high dose folate/B6 and 1,000 } \mu \mathrm{g} \text { of cyanocobalamin showed harm in patients with diabetic nephropathy, accelerated decline of } \\
\text { renal function and a doubling of cardiovascular events; all these events occurred in patients with a GFR }<50 \mathrm{~mL} / \mathrm{min} / 1.73 \mathrm{~m}^{2.9}\end{array}$ \\
\hline 2010 & VITATOPS reported no benefit of folate/B6 with cyanocobalamin 500 ug daily.10 \\
\hline 2010 & $\begin{array}{l}\text { The French Su.Fol.OM3 study, with the best renal function of the studies and folate/B6 with only } 20 \mu \mathrm{g} \text { of cyanocobalamin showed a } 43 \% \text { reduction of stroke; the } \\
\text { report focused on the failure to reduce } \mathrm{MI} \text {, so this was not much noticed. }{ }^{11}\end{array}$ \\
\hline 2011 & $\begin{array}{l}\text { Spence and Stampfer hypothesized that harm from cyanocobalamin among study participants with impaired renal function obscured the benefit of B vitamins in } \\
\text { the earlier trials. }{ }^{13}\end{array}$ \\
\hline 2012 & $\begin{array}{l}\text { The VITATOPS subgroup analysis, excluding patients who received antiplatelet agents, reported a } 24 \% \text { reduction of stroke with folate/B6 and cyanocobalamin } \\
500 \mu \mathrm{g} \text { daily. }{ }^{14}\end{array}$ \\
\hline $2015-16$ & $\begin{array}{l}\text { The CSPPT showed that folic acid reduced the risk of stroke by } 25 \% \text { in the main study, reduced stroke by } 30 \% \text { in participants with LDL-C }>2 \mathrm{mmol} / \mathrm{L}(76 \mathrm{mg} / \mathrm{dL} \text { ) } \\
\text { and was beneficial in participants with eGFR }<60 \mathrm{~mL} / \mathrm{min} / 1.73 \mathrm{~m}^{2} .{ }^{16}\end{array}$ \\
\hline 2017 & $\begin{array}{l}\text { Patient-level data from VISP and VITATOPS, and meta-analyses stratified by renal function and dose of cyanocobalamin, confirmed that harm from } \\
\text { cyanocobalamina among participants with impaired renal function obscured the benefit of B vitamins. In patients with good renal function and low doses or } \\
\text { no cyanocobalamin, it was demonstrated that B vitamins reduced the risk of stroke. The authors recommended the use of methylcobalamin or oxocobalamin } \\
\text { instead of cyanocobalamin.17 }\end{array}$ \\
\hline
\end{tabular}

CSPPT = China Stroke Primary Prevention Trial; DIVINe = Diabetic Intervention with Vitamin in Nephropathy; eGFR = estimated glomerular filtration rate; GFR = glomerular filtration rate; $\mathrm{HOPE}-2=$ Heart Outcomes Prevention Evaluation 2; LDL-C = low density lipoprotein cholestrol, $\mathrm{MI}=$ myocardial infarction; NORVIT = Norwegian Vitamin Trial; tHCy = total homocysteine; Su.Fol.OM3 = SUpplementation with FOlate, vitamin B6 and B12 and/or OMega-3 fatty acids; VISP = Vitamin Intervention to Prevent Stroke; VITATOPS = VITAmins TO Prevent Stroke.

In 2006, the Norwegian Vitamin Trial (NORVIT) ${ }^{6}$ and the Heart Outcomes Prevention Evaluation 2 (HOPE-2) trial ${ }^{7}$ were published in the same edition of the New England Journal of Medicine. The NORVIT trial showed no benefit of B vitamin therapy, and even showed harm among participants receiving cyanocobalamin. The HOPE-2 trial actually showed a $25 \%$ reduction of stroke with $\mathrm{B}$ vitamins that was arguably misinterpreted by the authors because they found no reduction of myocardial infarction. Being cardiologists, and perhaps unaware of the cerebral circulation, they may not have conceived a biological difference between myocardial infarction and stroke, so concluded that the reduction of stroke was a chance finding. However, stroke and myocardial infarction are not the same. Myocardial infarctions are virtually all caused by a plaque rupture with occlusion of a coronary artery; most strokes are due to small vessel disease, or to embolization from the carotid arteries, the aorta, or the heart. High levels of tHcy quadruple the risk of stroke in atrial fibrillation, ${ }^{19}$ increase venous thrombosis, and are associated with microemboli in patients with carotid stenosis.

In the same edition of the New England Journal of Medicine, an editorial by Loscalzo $^{8}$ hypothesized that the failure to show benefit of $B$ vitamins was due to toxicity from high doses of folic acid. All of this led to the conclusion by most physicians that "homocysteine is dead".
Figure 1: Homocysteine metabolism

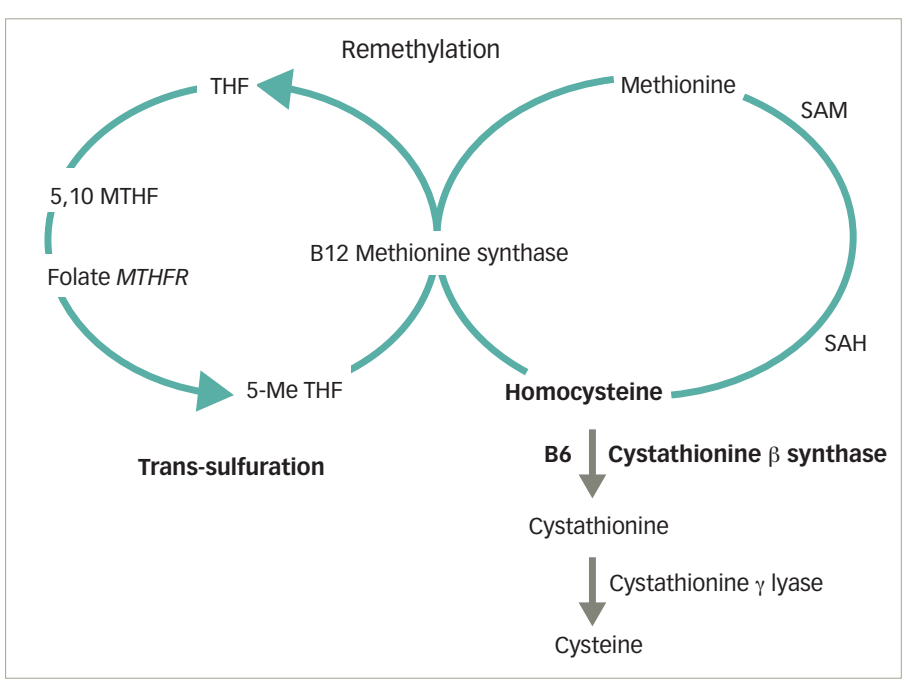

5-Me THF = 5-methyl tetrahydrofolate; $B 12=$ cobalamin; $B 6=$ pyridoxine; $M T H F=$ methylenetetrahydrofolate; $M T H F R=$ methylenetetrahydrofolate reductase; SAH = S-adenosylhomocysteine; SAM = S-adenosylmethionine; $T H F=$ tetrahydrofolate Reproduced with permission from Spence et al. 2017. ${ }^{15}$ 
Figure 2: Benefit of B vitamins in the VISP trial

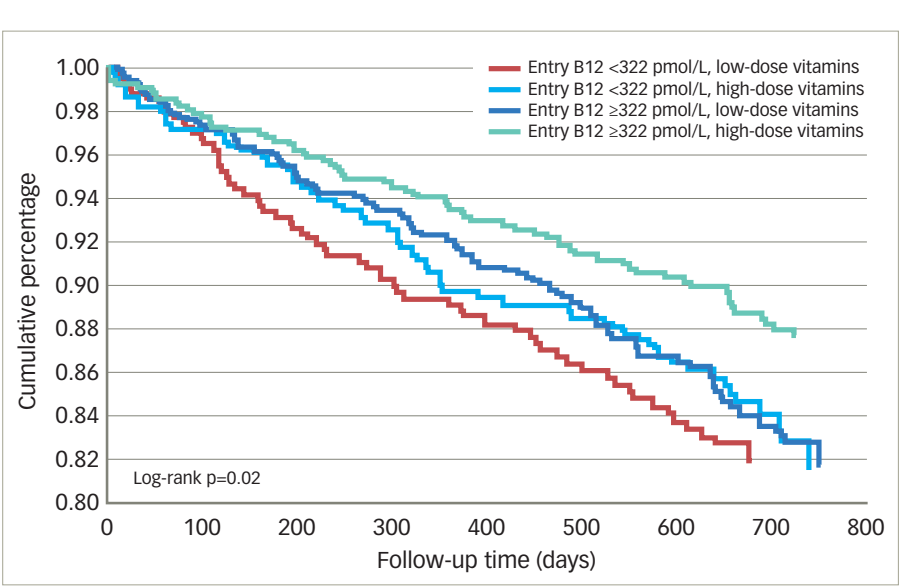

In this post-hoc analysis of the VISP trial the following participants were excluded: participants with serum cyanocobalamin below the 25 th percentile (250 pmol/L; to exclude those who received cyanocobalamin injections); participants with serum cyanocobalamin above the 95 th percentile $(950 \mathrm{pmol} / \mathrm{L}$; to exclude those receiving cyanocobalamin supplements outside the study); and participants with the lowest 10\% of eGFRs, as calculated by the Cockcroft-Gault equations (eGFR $<46.18 \mathrm{~mL} / \mathrm{min} / 1.73 \mathrm{~m}$ ). Survival free of stroke or myocardial infarction, and cardiovascular death was stratified by treatment arm (high-dose versus low-dose B vitamins) and by baseline serum cyanocobalamin, cut off at the median (322 pmol/L) to define groups more able and less able to absorb the vitamin. A $34 \%$ reduction in the number of events was observed in the participants with a baseline serum cyanocobalamin above the median who received high-dose $B$ vitamins including cyanocobalamin (400 $\mu \mathrm{g}$ daily) compared with those with a baseline serum cyanocobalamin below the median who received low-dose study vitamins. eGFR=estimated glomerular filtration rate; VISP = Vitamin Intervention to Prevent Stroke. Reproduced with permission from Spence et al., $2017^{15}$ and Spence et al., 2005. ${ }^{5}$

In 1999, I had reported with colleagues that among dialysis patients, $5 \mathrm{mg}$ daily of folic acid did not reduce tHcy compared with $1 \mathrm{mg}$ daily. ${ }^{20}$ । thought, therefore, that B vitamins would not be effective in patients with renal impairment. Taken with the effect of B12 injections among patients with low B12 levels at baseline, this may have obscured the benefit of B vitamins in the VISP trial. We therefore carried out a subgroup analysis in the VISP study population, excluding 1,525/3,680 participants who received B12 injections, and/or had impaired renal function with an estimated glomerular filtration rate in the lowest decile (below $48 \mathrm{~mL} / \mathrm{min} / 1.73 \mathrm{~m}^{2}$ )..$^{5}$ In the remaining subgroup of 2,155 patients, the median baseline serum B12 was $322 \mathrm{pmol} / \mathrm{L}$.

Figure 2 shows the result of that study. ${ }^{5,15}$ Participants with a baseline serum B12 above the median (meaning they could absorb B12 well) and who had received high-dose $\mathrm{B}$ vitamins had a $34 \%$ reduction of stroke, myocardial infarction, and vascular death compared with those whose baseline B12 was below the median and received low-dose vitamins.

In 2010, the Diabetic Intervention with Vitamin in Nephropathy (DIVINe) study was published. Patients with diabetic nephropathy were randomized to high-dose B vitamins, containing folic acid $5 \mathrm{mg}$, B6 $25 \mathrm{mg}$ and cyanocobalamin $1,000 \mu g$ daily versus placebo. We found that $B$ vitamins were harmful, accelerating the decline of renal function, and doubling cardiovascular events (Figure 3). ${ }^{9}$ All the events occurred in participants with a glomerular filtration rate of $<50 \mathrm{~mL} / \mathrm{min} / 1.73 \mathrm{~m}^{2}{ }^{21}$

After this study, I received emails pointing out that Koyama et al. had reported that patients with renal failure had high levels of thiocyanate. ${ }^{22}$ They had also reported that in patients with renal failure, methylcobalamin
Figure 3: Effect of B vitamins on the risk of a composite cardiovascular outcome in patients with diabetic nephropathy in the DIVINe trial

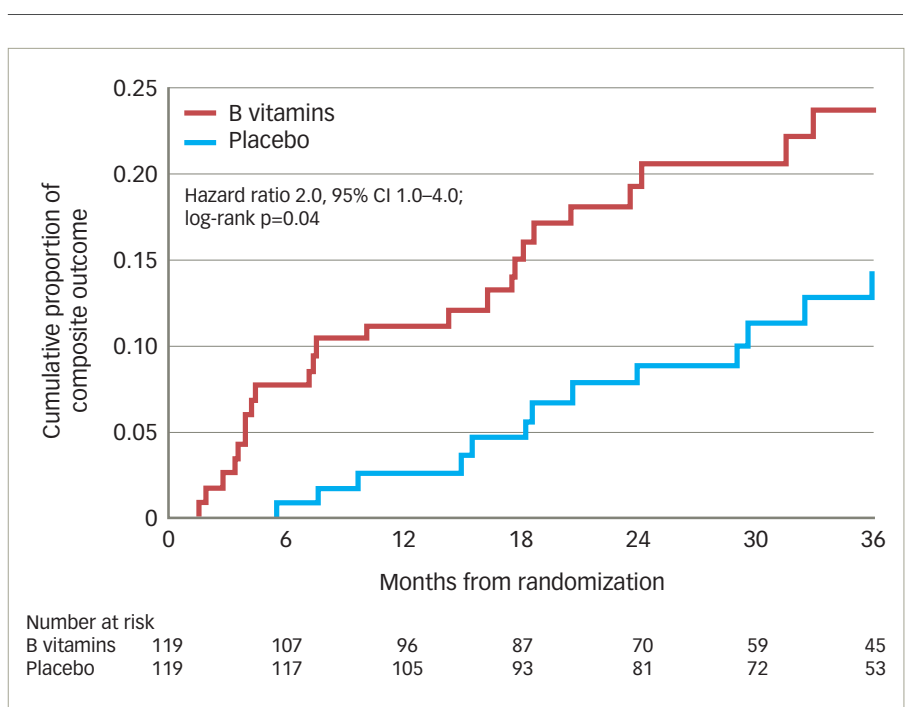

Cumulative proportion of myocardial infarction, stroke, revascularization and all-cause mortality in the DIVINe trial. Following treatment with B vitamins (2.5 mg folic acid, $25 \mathrm{mg}$ pyridoxine and 1,000 $\mu \mathrm{g}$ cyanocobalamin daily), the 36-month risk of the composite outcome was $23.5 \%$ in the treatment group and $14.4 \%$ in the placebo group (log-rank $p=0.04$ ). All the events occurred in participants with a glomerular filtration rate of less than $50 \mathrm{~mL} / \mathrm{min} / 1.73 \mathrm{~m}^{2}$. $\mathrm{Cl}=$ confidence interval; DIVINe = Diabetic Intervention with Vitamin in Nephropathy. Reproduced with permission from Spence et al., 2017. ${ }^{15}$ and House et al., 2010.9

Figure 4: Polynomial and inverse regression, spline, loess fits for plasma total homocysteine with B12

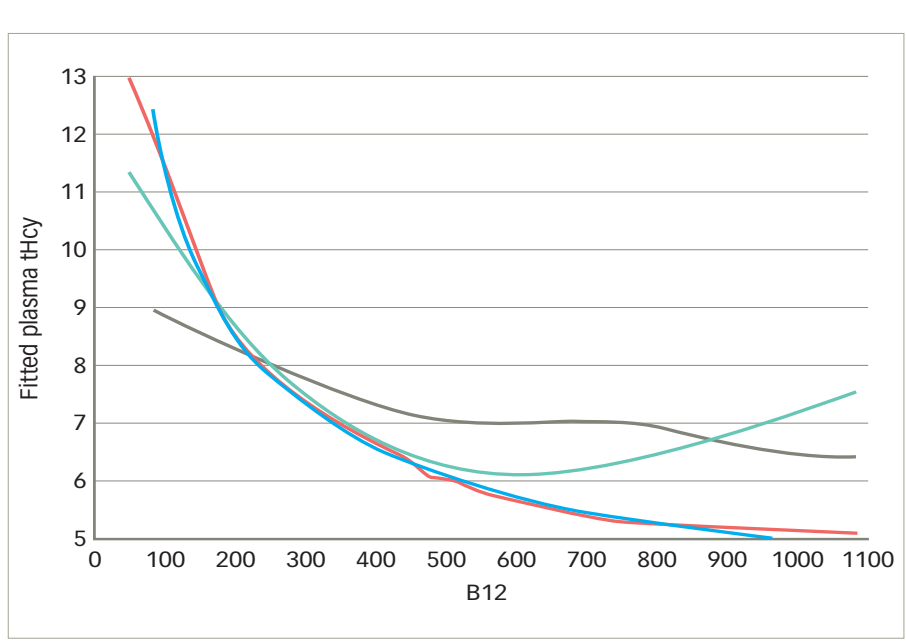

Unadjusted analysis. Red, green, blue and grey lines represent loess, cubic polynomials, cubic polynomials of the inverse covariate and smooth splines respectively. tHCy = total homocysteine.

Reproduced with permission from Bang et al., 2006. ${ }^{32}$

lowered levels of both tHcy and asymmetric dimethylarginine (ADMA; a nitric oxide antagonist that is an evil companion of homocysteine), ${ }^{23}$ whereas in a Norwegian study, cyanocobalamin did not lower levels of ADMA. ${ }^{24}$

In 2010, the Australian VITAmins TO Prevent Stroke (VITATOPS) trial reported no benefit of folate/B6 and cyanocobalamin $500 \mu \mathrm{g}$ daily in the main study:10 later they reported that B vitamins reduced stroke by $24 \%$ in a subgroup that did not receive antiplatelet agents. ${ }^{13}$ 
Table 2: Dose of cyanocobalamin, renal function and reduction of stroke or cardiovascular events

\begin{tabular}{|c|c|c|c|c|c|}
\hline \multirow[t]{2}{*}{ Trial } & \multirow[t]{2}{*}{$\begin{array}{l}\text { Dose of } \\
\text { cyanocobalamin }\end{array}$} & \multicolumn{2}{|c|}{$\begin{array}{l}\text { Serum creatinine } \\
\left(\mu \mathrm{mol} / \mathrm{L}^{*}\right)\left(\mathrm{SD} \text { or } 95 \% \mathrm{Cl}{ }^{* *}\right)\end{array}$} & \multirow[t]{2}{*}{ HR of stroke $(95 \% \mathrm{Cl})$} & \multirow[t]{2}{*}{ p-value } \\
\hline & & Active & Control & & \\
\hline $\mathrm{DIVINe}^{9}$ & $1,000 \mu g$ & $141.4(97.2)$ & $123.8(79.6)$ & $6.6(0.8-54.4)$ & 0.08 \\
\hline $\mathrm{VISP}^{4}$ & $400 \mu g$ & $99.9(55.7)$ & $97.2(47.7)$ & $1.0(0.8-1.3)$ & 0.80 \\
\hline SEARCH ${ }^{25}$ & $1,000 \mu g$ & N/A & N/A & $1.02(0.86-1.21)$ & N/A \\
\hline VITATOPS ${ }^{10}$ & $500 \mu g$ & $92.4(40.3)$ & $91.4(34.6)$ & $0.92(0.81-1.06)$ & 0.25 \\
\hline NORVIT ${ }^{6}$ & $400 \mu g$ & $91.0(27.0)$ & $91.0(24.0)$ & $0.83(0.47-1.47)$ & 0.52 \\
\hline HOPE-2 $2^{7}$ & $1,000 \mu g$ & $88.4(26.5)$ & $88.4(26.5)$ & $0.75(0.59-0.97)$ & 0.03 \\
\hline SU.Fol.OM326 & $20 \mu \mathrm{g}$ & $78.0(70.0-88.0)^{\star *}$ & $78.0(69.0-88.0)^{* *}$ & $0.57(0.33-0.97)$ & 0.04 \\
\hline CSPPT (all) $)^{14}$ & $0 \mu g$ & $65.95(19.0)$ & $65.95(19.0)$ & $0.79(0.68-0.93)$ & 0.003 \\
\hline CSPPT with eGFR $<60 \mathrm{~mL} / \mathrm{min} / 1.73 \mathrm{~m}^{2}$ & $0 \mu g$ & $126.6(72.7)$ & $130.6(68.6)$ & $0.88(0.33-2.36)$ & 0.81 \\
\hline \multirow[t]{2}{*}{ CSPPT excluding eGFR $<60 \mathrm{~mL} / \mathrm{min} / 1.73 \mathrm{~m}^{2}$} & $0 \mu g$ & $64.7(13.8)$ & $64.6(13.6)$ & $0.79(0.67-0.92)$ & 0.003 \\
\hline & & \multicolumn{2}{|c|}{ eGFR $\left(\mathrm{mL} / \mathrm{min} / 1.73 \mathrm{~m}^{2}\right)(\mathrm{SD})$} & \multicolumn{2}{|l|}{$\begin{array}{l}\text { HR for } \mathrm{Ml} \text {, stroke } \\
\text { and/or death }(95 \% \mathrm{Cl})\end{array}$} \\
\hline \multicolumn{6}{|l|}{ VISP4 } \\
\hline eGFR $<50 \mathrm{~mL} / \mathrm{min} / 1.73 \mathrm{~m}^{2}$ & $400 \mu g$ & $38.7(9.2)$ & $39.3(8.6)$ & $1.01(0.74-1.37)$ & 0.977 \\
\hline eGFR $\geq 50 \mathrm{~mL} / \mathrm{min} / 1.73 \mathrm{~m}^{2}$ & $400 \mu g$ & $89.2(44.6)$ & $87.3(31.1)$ & $0.92(0.77-1.11)$ & 0.382 \\
\hline \multicolumn{6}{|l|}{ VITATOPS ${ }^{10}$} \\
\hline eGFR $<50 \mathrm{~mL} / \mathrm{min} / 1.73 \mathrm{~m}^{2}$ & $500 \mu g$ & $38.6(10.0)$ & $38.3(9.5)$ & $0.88(0.59-1.32)$ & 0.54 \\
\hline eGFR $>50 \mathrm{~mL} / \mathrm{min} / 1.73 \mathrm{~m}^{2}$ & $500 \mu g$ & $80.2(18.1)$ & 80.9 (18.3) & $0.82(0.68-0.98)$ & 0.03 \\
\hline \multicolumn{6}{|c|}{$\begin{array}{l}\text { *Conversions from mg/dL performed using www.endmemo.com/medical/unitconvert/Creatinine.php (accessed March 28, 2018). } \\
\text { **Ranges between parentheses denote } 95 \% \text { confidence intervals; single numbers denote standard deviations. } \\
\text { CI= confidence interval; CSPPT = China Stroke Primary Prevention Trial; DIVINe = Diabetic Intervention with Vitamin in Nephropathy; eGFR = estimated glomerular filtration rate; } \\
\text { HOPE-2 = Heart Outcomes Prevention Evaluation 2; HR = hazard ratio; MI = myocardial infarction; N/A = not applicable; NORVIT = Norwegian Vitamin Trial; SD = Standard deviation; } \\
\text { SEARCH = Study of the Effectiveness of Additional Reductions in Cholesterol and Homocysteine; Su.Fol. OM3 = SUpplementation with FOlate, vitamin B6 and B12 and/Or OMega-3 fatty } \\
\text { acids; VISP = Vitamin Intervention to Prevent Stroke; VITATOPS = VITAmins TO Prevent Stroke. Reproduced with permission from Spence et al., } 2017 .{ }^{15}\end{array}$} \\
\hline
\end{tabular}

Also in 2010, the French vitamin study, SUpplementation with FOlate, vitamin B6 and B12 and/or OMega-3 fatty acids (Su.Fol.OM3) was published. ${ }^{11}$ In this study the dose of cyanocobalamin was only $20 \mu \mathrm{g}$ daily, and the renal function was much better than in the other studies (Table 2). ${ }^{4,67,7,19,10,14,25,26}$ The reduction of stroke was $43 \%$.

In 2011, I hypothesized with Stampfer that harm from cyanocobalamin among study participants with renal impairment had obscured the benefit of $\mathrm{B}$ vitamins in the earlier trials. ${ }^{12}$

Then in 2015, the final piece of the puzzle fell into place. The China Stroke Primary Prevention Trial (CSPPT) reported that in China, where folate fortification does not exist, folic acid reduced stroke in primary prevention by $25 \% .{ }^{14}$ In higher-risk patients with low density lipoprotein cholesterol (LDL-C) of $>2 \mathrm{mmol} / \mathrm{L}$, folic acid reduced stroke by $30 \% .{ }^{27}$ crucially, folic acid was beneficial among study participants with impaired renal function. ${ }^{28}$

In 2017, with Yi and Hankey, we performed a meta-analysis of the trials stratified by dose of cynanocobalamin and by renal function. In addition, we analyzed patient-level data from the VISP trial and the VITAPOPS trial. What emerged was that harm from high-dose cyanocobalamin among study participants obscured the benefit of B vitamins among study participants with good renal function. ${ }^{15}$
In line with this analysis, it turns out that besides folic acid and possibly vitamin B6, we should perhaps be using methylcobalamin or oxocobalamin, not cyanocobalamin, to prevent stroke.

This is important because in the era of folate fortification, B12 is the major determinant of elevated tHcy. ${ }^{29,30}$ Unrecognized metabolic B12 deficiency is very common, and usually missed. ${ }^{31}$ Measuring total serum B12 does not accurately assess metabolic adequacy of B12 because a small and variable fraction is active ( 6-20\%). Thus, among patients with a total serum B12 in the reference range ( 60-600 pmol/L), many patients have metabolic B12 deficiency. In order to assess metabolic adequacy of serum B12 it is necessary to measure holotranscobalamin, or one of the metabolites that are elevated in B12 deficiency: methylmalonic acid (MMA), or tHcy. ${ }^{31}$ The serum B12 level below which MMA or tHcy begins to rise is $400 \mathrm{pmol} / \mathrm{L}$ (Figure 4). ${ }^{31,32}$ So among patients referred to a stroke prevention clinic, $10 \%$ of patients aged below 50 years had metabolic B12 deficiency; above the age of 71 years it was $30 \% .^{33}$ In our community this appears to be declining as physicians become more aware of the issue.

\section{Conclusion}

Based on recent findings, it is now clear that B vitamins to lower homocysteine do prevent stroke. It is possible that this was obscured in the early trials by harm from cyanocobalamin among participants with 
impaired renal function. Metabolic B12 deficiency is very common, often missed, and raises levels of tHcy. In the era of folate fortification, B12 is the major nutritional determinant of elevated tHcy. Folate alone is therefore probably not the optimal therapy to lower tHcy. We should probably be using folate (and possibly B6) with methylcobalamin or oxocobalamin instead of cyanocobalamin. $\square$
1. McCully KS. Vascular pathology of homocysteinemia: Implications for the pathogenesis of atherosclerosis Am J Pathol 1969:56:111-28.

2. Boers GHJ, Trijbels FJM, Fowler B, et al. Heterozygosity for homocystinuria in premature peripheral and cerebral occlusive arterial disease. N Eng/ J Med. 1985;313:709-14.

3. Graham IM, Daly L, Refsum H, et al. Plasma homocysteine as a risk factor for vascular disease. JAMA. 1997;277:1775-81.

4. Toole JF, Malinow MR, Chambless LE, et al. Lowering plasma total homocysteine to prevent recurrent stroke, myocardial infarction, and death in ischemic stroke patients: Results of the vitamin intervention for stroke prevention (VISP) randomized trial. JAMA. 2004;291:565-75.

5. Spence JD, Bang H, Chambless LE, Stampfer MJ. Vitamin intervention for stroke prevention trial: An efficacy analysis. Stroke. 2005;36:2404-09.

6. Bønaa KH, Njolstad I, Ueland PM, et al. Homocysteine lowering and cardiovascular events after acute myocardial infarction $N$ Eng/ J Med 2006:354:1578-88.

7. Lonn E, Yusuf S, Arnold MJ, et al. Homocysteine lowering with folic acid and B vitamins in vascular disease. N Eng/ J Med. 2006;354:1567-77.

8. Loscalzo J. Homocysteine trials--clear outcomes for complex reasons. N Eng/ J Med. 2006;354:1629-32.

9. House AA, Eliasziw M, Cattran DC, et al. Effect of B-vitamin therapy on progression of diabetic nephropathy: $\mathrm{A}$ randomized controlled trial. JAMA. 2010:303:1603-9.

10. VITATOPS Trial Study Group. B vitamins in patients with recent transient ischaemic attack or stroke in the vitamins to prevent stroke (VITATOPS) trial: a randomised, double-blind, parallel, placebo-controlled trial. Lancet Neurol. 2010;9:855-65.

11. Galan P, Kesse-Guyot E, Czernichow S, et al. SU.FOL.OM 3 Collaborative Group. Effects of B vitamins and omega 3 fatty acids on cardiovascular diseases: a randomised placebo controlled trial. BMJ. 2010:341:c6273.

12. Spence JD, Stampfer MJ. Understanding the complexity of homocysteine lowering with vitamins: The potential role of subgroup analyses. JAMA. 2011;306:2610-1.
13. Hankey GJ, Eikelboom JW, Yi Q, et al. Antiplatelet therapy and the effects of $B$ vitamins in patients with previous stroke or transient ischaemic attack: A post-hoc subanalysis of VITATOPS, a randomised, placebo-controlled trial. Lancet Neurol. 2012;11:512-20.

14. Huo $Y$, Li J, Qin $X$, et al. Efficacy of folic acid therapy in primary prevention of stroke among adults with hypertension in China: The CSPPT randomized clinical trial. JAMA. 2015:313:1325-35.

15. Spence JD, Yi Q, Hankey GJ. B vitamins in stroke prevention: Time to reconsider. Lancet Neurol. 2017:16:750-60.

16. Spence JD. Homocysteine-lowering therapy: A role in stroke prevention? Lancet Neurology. 2007;7:830-38

17. Nygård $\mathrm{O}$, Nordehaug JE, Refsum $\mathrm{H}$, et al. Plasma homocysteine levels and mortality in patients with coronary artery disease. $N$ Engl J Med. 1997;337:230-6.

18. Spence JD, Howard VJ, Chambless LE, et al. Vitamin intervention for stroke prevention (VISP) trial: Rationale and design. Neuroepidemiology 2001:20:16-25.

19. Poli D, Antonucci $E$, Cecchi $E$, et al. Culprit factors for the failure of well-conducted warfarin therapy to prevent ischemic events in patients with atrial fibrillation: The role of homocysteine. Stroke. 2005;36:2159-63

20. Spence JD, Cordy P, Kortas C, Freeman D. Effect of usual doses of folate supplementation on elevated plasma homocyst(e)ine in hemodialysis patients: No difference between 1 and $5 \mathrm{mg}$ daily. Am I Nephrol. 1999:18:405-10.

21. Spence JD, Eliasziw M, House AA. B-vitamin therapy for diabetic nephropathy: Reply. JAMA. 2010;304:636-7.

22. Koyama K, Yoshida A, Takeda A, et al. Abnormal cyanide metabolism in uraemic patients. Nephrol Dial Transplant. 1997; 12:1622-8

23. Koyama K, Ito A, Yamamoto J, et al. Randomized controlled trial of the effect of short-term coadministration of methylcobalamin and folate on serum adma concentration in patients receiving longterm hemodialysis. Am J Kidney Dis. 2010:55:1069-78.

24. Loland $\mathrm{KH}$, Bleie $\mathrm{O}$, Borgeraas $\mathrm{H}$, et al. The association between progression of atherosclerosis and the methylated amino acids asymmetric dimethylarginine and trimethyllysine. PLOS One. 2013;8:e64774.

25. Study of the Effectiveness of Additional Reductions in Cholesterol and Homocysteine (SEARCH) Collaborative Group, Armitage JM, Bowman L, Clarke RJ, et al. Effects of homocysteine-lowering with folic acid plus vitamin B12 vs placebo on mortality and major morbidity in myocardial infarction survivors: a randomized trial. JAMA. 2010;303: 2486-94.

26. Andreeva VA, Galan $P$, Torrès $M$, et al. Supplementation with $B$ vitamins or $n-3$ fatty acids and depressive symptoms in cardiovascular disease survivors: ancillary findings from the SUpplementation with FOLate, vitamins B-6 and B-12 and/or OMega-3 fatty acids (SU.FOL.OM3) randomized trial. Am I Clin Nutr. 2012;96:208-14.

27. Qin X, Li J, Spence JD, et al. Folic acid therapy reduces the first stroke risk associated with hypercholesterolemia among hypertensive patients. Stroke. 2016;47:2805-12.

28. Xu X, Qin X, Li Y, et al. Efficacy of folic acid therapy on the progression of chronic kidney disease: The renal substudy of the china stroke primary prevention trial. JAMA Intern Med. 2016;176:1443-50

29. Quinlivan EP, MCPartlin J, MCNulty H, et al. Importance of both folic acid and vitamin B12 in reduction of risk of vascular disease. Lancet. 2002;359:227-8.

30. Robertson J, lemolo F, Stabler SP, et al. Vitamin B12, homocysteine and carotid plaque in the era of folic acid fortification of enriched cereal grain products. CMAJ. 2005;172:1569-73.

31. Spence JD. Metabolic vitamin B12 deficiency: A missed opportunity to prevent dementia and stroke. Nutr Res. 2016;36:109-16.

32. Bang H, Mazumdar M, Spence JD. Tutorial in biostatistics: Analyzing associations between total plasma homocysteine and $B$ vitamins using optimal categorization and segmented regression. Neuroepidemiology. 2006;27:188-200.

33. Spence JD. Nutrition and stroke prevention. Stroke. 2006;37: 2430-5. 